\title{
Pivotal clinical dilemmas in collagen vascular diseases associated with
} interstitial lung involvement

\author{
K.M. Antoniou, G. Margaritopoulos, F. Economidou and N.M. Siafakas
}

ABSTRACT: The connective tissue disorders (CTDs), also called collagen vascular diseases (CVDs), represent a heterogeneous group of immunologically mediated inflammatory disorders with a large variety of affected organs. Individuals with a CTD (rheumatoid arthritis, systemic lupus erythematosus, systemic sclerosis, Sjögren's syndrome, polymyositis/dermatomyositis and mixed connective tissue disease) are susceptible to respiratory involvement. When the lungs are affected, an increasing mortality and morbidity in CVDs occurs. Interstitial lung disease (ILD) is established as a clinical corollary across the spectrum of CTDs, with an overall incidence estimated at $15 \%$.

Therefore, pivotal clinical dilemmas remain in the evaluation and management of ILD involvement in CVDs. Critical questions are the presence of fibrosis and whether the disease is clinically significant. Moreover, the clinician has to decide if treatment is warranted and which is the best therapeutic approach. The use of additional tests, such as pulmonary function tests, high-resolution computed tomography scan, bronchoalveolar lavage fluid and surgical lung biopsy, deserves better discussion. The present review focuses on establishing the diagnosis of ILD in CTD, and on evaluating disease activity and prognosis. This will provide the basis for therapeutic decisions that will be discussed, including an overview of recent advances.

KEYWORDS: Bronchoalveolar lavage fluid, collagen vascular diseases, connective tissue disorders, interstitial lung disease, pulmonary fibrosis, treatment

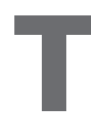
he connective tissue disorders (CTDs), also called collagen vascular diseases (CVDs), represent a heterogeneous group of immunologically mediated inflammatory disorders with a large variety of affected organs. Individuals with a CTD (rheumatoid arthritis (RA), systemic lupus erythematosus (SLE), systemic sclerosis (SSc), Sjögren's syndrome (SS), polymyositis (PM)/dermatomyositis (DM) and mixed connective tissue disease (MCTD)) are susceptible to respiratory involvement.

All components of the respiratory system may be affected, i.e. airways, vessels, parenchyma, pleura and respiratory muscles. The frequency, clinical presentation, prognosis and response to therapy vary, depending on the pattern of involvement along with the underlying CTD. Interstitial lung disease (ILD) is an established clinical corollary across the spectrum of CTDs, with an overall incidence estimated at $15 \%$ (table 1). Rates of ILD differ between these CTDs. Using high-resolution computed tomography (HRCT) to detect ILD in CTD patient cohorts (cohort sizes ranging 21-156), prevalence varies from $19 \%$ in RA to $67 \%$ and $85 \%$ in MCTD and diffuse SSc, respectively [1-3]. Intermediate prevalence, in the range $23-38 \%$, is found in SLE and DM/PM. Interstitial lung involvement is usually referred to as interstitial pneumonia (IP). IPs can be further subdivided into several histopathological/radiological entities: nonspecific interstitial pneumonia (NSIP), usual interstitial pneumonia (UIP), organising pneumonia $(\mathrm{OP})$, respiratory bronchiolitis-associated ILD, desquamative IP, diffuse alveolar damage (DAD) and lymphocytic interstitial pneumonia (LIP). Classification of NSIP has been further subdivided in two groups, namely cellular and fibrotic NSIP [2]. As all seven pathological types are also seen in CVD-IP, the same classification is applied.

Early detection of pulmonary involvement is very important for the initiation of targeted therapy, because the damage to the lung parenchyma may
AFFILIATIONS

Dept of Thoracic Medicine, Medical School, University of Crete Heraklion, Greece.

\section{CORRESPONDENCE}

N.M. Siafakas

Dept. of Thoracic Medicine, University General Hospital, Medical School

University of Crete

71110 Heraklion

Greece

Fax: 302810542650

E-mail: siafak@med.uoc.gr

Received:

November 142007

Accepted after revision:

November 102008

STATEMENT OF INTEREST None declared.

Online ISSN 1399-3003 


\begin{tabular}{|c|c|c|}
\hline TABLE 1 & \multicolumn{2}{|c|}{$\begin{array}{l}\text { Interstitial lung involvement in connective tissue } \\
\text { diseases }\end{array}$} \\
\hline \multicolumn{2}{|c|}{ Rheumatoid arthritis } & $\begin{array}{l}\text { Usual interstitial pneumonia } \\
\text { Nonspecific interstitial pneumonia } \\
\text { Organising pneumonia } \\
\text { Rheumatoid nodules }\end{array}$ \\
\hline \multicolumn{2}{|c|}{ Systemic sclerosis } & $\begin{array}{l}\text { Nonspecific interstitial pneumonia } \\
\text { Usual interstitial pneumonia }\end{array}$ \\
\hline \multicolumn{2}{|c|}{ Sjögren's syndrome } & $\begin{array}{l}\text { Nonspecific interstitial pneumonia } \\
\text { Lymphocytic interstitial pneumonia } \\
\text { Usual interstitial pneumonia } \\
\text { Desquamative interstitial pneumonia }\end{array}$ \\
\hline \multicolumn{2}{|c|}{ Polymyositis/dermatomyositis } & $\begin{array}{l}\text { Lymphocytic interstitial pneumonia } \\
\text { Organising pneumonia } \\
\text { Diffuse alveolar damage }\end{array}$ \\
\hline \multicolumn{2}{|c|}{$\begin{array}{l}\text { Systemic lupus erythemato- } \\
\text { sous }\end{array}$} & $\begin{array}{l}\text { Acute interstitial pneumonitis } \\
\text { Lymhocytic interstitial pneumonia } \\
\text { Nonspecific interstitial pneumonia } \\
\text { Usual interstitial pneumonia } \\
\text { Desquamative interstitial pneumonia }\end{array}$ \\
\hline
\end{tabular}

already be irreversible at the time of the onset of respiratory symptoms. It is now recommended that all patients with CVD are checked for IP $[1,3]$. Routine checking includes clinical evaluation, lung function and clinical exercise tests, imaging modalities, bronchoalveolar lavage (BAL), lung biopsy and use of some serum biomarkers.

Conversely, ILD may be the first or sole recognised manifestation of a CTD. As the clinical features of the CTDs may be subtle, it is often difficult for clinicians to identify an underlying CTD in individuals who present with ILD. It can be especially challenging to accurately characterise patients with subtle manifestations of CVDs. However, in some patients, lung involvement precedes other systemic symptoms, making the distinction between idiopatic NSIP and lung involvement of CTD impossible at the time of diagnosis. It is plausible that a significant proportion of idiopathic NSIP is undifferentiated CTD, a clinical entity with symptoms and/or signs of a CTD, but not fulfilling the classification of any specific diagnostic entity [4].

\section{RHEUMATOID ARTHRITIS}

RA is a systemic destructive, inflammatory disease affecting $\sim 1-$ $2 \%$ of the general population [1, 3]; the most common CVD [3]. Nearly $50 \%$ of the patients present extra-articular manifestations involving skin, eye, heart and lungs $[5,6]$. Clinically, these manifestations are dominated by pulmonary, cardiac and vascular changes. Although cardiovascular disease is responsible for the majority of RA-related deaths, pulmonary complications are common and cause $10-20 \%$ of overall mortality [6]. The majority of lung disease occurs in the first 5 yrs after initial diagnosis, and may be the presenting manifestation in $10-20 \%$ of patients. The most common pulmonary manifestations are pleural abnormalities and ILD [2]. The prevalence of ILD in RA varies depending on the criteria used to establish the diagnosis.

\section{Histopathology}

Unlike in most other CTDs, in RA the UIP pattern is more commonly seen on surgical lung biopsy than NSIP [7, 8]. RA patients who develop pulmonary fibrosis are often younger than those with idiopathic UIP. Cigarette smoking has been reported to be an independent predictor of lung disease in RA [9]. In the study by LEE et al. [7], 42 patients with RA underwent lung biopsy and were diagnosed as having IP. In $70 \%$ of these patients HRCT findings, such as lower lobedominant bilateral subpleural reticular opacities with honeycombing and absence of ground glass opacities, supported the evidence of an UIP pattern. In the study by YOSHINOUCHI et al. [8], most patients with UIP pattern on biopsy had honeycombing and reticulonodular opacities on HRCT, whereas patients with NSIP had no honeycombing on HRCT. Only in the study by TANAKA et al. [10] NSIP was observed to be the predominant pattern on lung biopsy, but only four out of 26 patients with UIP pattern on HRCT underwent lung biopsy. LIP and OP have also been described $[11,12]$. In addition, acute interstitial pneumonia (AIP) is quite uncommon in RA $[13,14]$.

The above pathological patterns described in RA-ILD have prognostic significance. Recently, PARK et al. [15], in a large series of 362 patients (269 patients with IP and 93 with CVD), have observed that prognosis in patients with CVD-UIP is better than in patients with idiopathic pulmonary fibrosis (IPF)-UIP. As a subgroup, the RA patients with IP also had a better prognosis than those with IPF, despite the same histopathological pattern of UIP [13].

More than any other rheumatic disease, patients with RAassociated lung disease tend to manifest concurrent acute, subacute and chronic histopathology, all in the same surgical biopsy. Thus, a combination of acute, subacute and chronic inflammatory reactions, including involvement of the pleura, should always raise consideration of RA disease. Vasculitis and pulmonary haemorrhage have been described as acute pulmonary manifestations of RA. Rheumatoid nodules may be difficult to distinguish from granulomatous infection and Wegener's granulomatosis. Knowledge of the clinical and radiological findings is often helpful in resolving this dilemma.

\section{Clinical and laboratory features}

Symptoms of RA usually precede lung involvement, but they can occur simultaneously, or RA can follow the diagnosis of IP $[8,16,17]$. The most frequent respiratory symptoms are progressive dyspnoea and dry cough even if, in many cases, dyspnoea on exercise may be masked by inactivity due to polyarthritis. Most patients have fine bibasilar crackles, but clubbing is less common than in patients with IPF [18].

Pulmonary function tests (PFTs) are invaluable in identifying CTD patients likely to have underlying ILD or pulmonary vascular disease. The most used parameters are total lung capacity (TLC), vital capacity (VC), forced expiratory volume in one second and diffusing capacity of the lung for carbon monoxide ( $D \mathrm{~L}, \mathrm{CO})$. Among routine PFTs, $D \mathrm{~L}, \mathrm{CO}$ is the most sensitive variable; a restrictive defect is typical but mixed patterns may also be seen [19, 20]. Reductions in volumes (especially the forced vital capacity (FVC) or TLC) are less sensitive. 
A reduced DL,CO may predict the progression of lung fibrosis, and DAWSON et al. [21] showed that a DL,CO $<54 \%$ of the predicted value is a highly specific predictor of disease progression. In case of normal lung volume, a reduced DL,CO may indicate pulmonary vascular disease.

Peak and functional exercise capacity are reduced in patients with CVD-IP, and this can be observed during cardiopulmonary exercise testing (CPET). Reduction in ventilatory capacity and gas exchange are the cause of reduction in exercise capacity. CPET is very important because it can help the diagnosis in early stage disease in patients with normal PFTs, normal chest radiography or normal HRCT by detecting an exercise-induced hypoxaemia and an increase of alveolararterial oxygen gradient $[22,23]$. Arterial desaturation can be observed using a 6-min walk test and pulse oximetry, even if hypoxaemia and desaturation might be hidden by hyperventilation [24, 25]. However, the aforementioned methodology gives a crude indication of a patient's exercise capacity, although myositis, wasting, anaemia, arthralgias and/or cardiac involvement may pose limiting factors.

\section{Radiological features}

The value of chest radiography is limited in the diagnosis of CVD-IPs. The HRCT findings in RA can be categorised as parenchymal, airways and pleural disease. HRCT is more specific and sensitive for the identification of IP and is abnormal in $>80 \%$ of patients with RA and suspected IP [26].

The pattern of radiographic abnormality seen on HRCT in RA has proved to be an excellent predictor of the underlying pathological pattern. Four radiographic patterns have been described: UIP, NSIP, OP and bronchiolitis. Three of the radiographic patterns, UIP, NSIP and OP, conform to those seen in idiopathic interstitial pneumonias (IIPs), and strongly correlate with the underlying pathology [14]. In detail, in patients without respiratory symptoms the prevalence of ground glass opacities is $3 \%$ and the prevalence of honeycombing is $0 \%$, in contrast to $26 \%$ and $23 \%$, respectively, in patients with respiratory symptoms [27]. However, there is one study which claims that the majority of the changes observed in HRCT are nonspecific and in only one patient has a pattern suggestive of IP been seen [28]. In patients with early onset RA the prevalence of IP is 33\%; a pattern of ground glass opacities is the most frequent [27, 29]. However, most studies have shown that a reticular pattern with honeycombing is a more frequent finding on HRCT than ground glass opacities, regardless of histological subtype [14, 19, 30-32]. Similar to the pathological patterns, these radiographic patterns also appear to predict progression and outcome in RA-ILD [19, 33]. In the study by TANAKA et al. [10], four patterns have been found to be more frequent; UIP, NSIP, OP and bronchiolitis. The lung biopsy in 17 patients revealed a histological pattern that reflects the findings of HRCT.

\section{Bronchoalveolar lavage}

BAL is not routinely used as a diagnostic modality in RAassociated ILD. The main value of BAL is to exclude complicating infections and malignancy, and to identify unusually high counts of one or more cell types indicating the possibility of coexisting disease (e.g. a striking eosinophilia could suggest a drug reaction in the appropriate clinical context). BAL can be abnormal in $52 \%$ of the patients with early onset RA revealing the presence of alveolitis [27]. A neutrophil alveolitis can be found in patients with clinically evident IP [31, 34, 35] and a lymphocitic alveolitis can be found in $33 \%$ of patients with normal chest radiography and PFTs [34].

\section{Lung biopsy}

Lung biopsy has an important role in the prognosis of IIPs but the fact that UIP seems to be rare in CVDs, with the possible exception of RA [36], and that the prognosis of CVD-UIP seems to be better than in IPF-UIP, has put in doubt that open lung biopsy is justified in patients with CVD-IIP, because its prognostic significance seems to be low.

\section{Treatment}

As far as the treatment of RA-IP is concerned, unfortunately there have not, as yet, been any randomised controlled trials. Therefore, therapy is essentially empirical. Corticosteroids are the first line therapy (prednisone $0.5-1 \mathrm{mg} \cdot \mathrm{kg}^{-1}$ ) and the best response has been observed in patients with RA-OP [37]. Immunosuppresive drugs such as azathioprine, cyclosporine, methotrexate (MTX) and cyclophosphamide are also used, either in association with corticosteroids for maintenance therapy or for corticosteroid-resistant forms.

The use of MTX in RA has been associated with MTX pneumonitis (MTX-P), which is observed in $0.5-12 \%$ of patients with RA [38]. There are three sets of criteria for the diagnosis of MTX-P [39-41]. The accepted changes of MTX-P on HRCT of the chest are patchy ground glass shadowing in any part of the lung that can be associated with micronodule formation and lymphadenopathy $[42,43]$. As HRCT is noninvasive and widely available, this investigation should be performed as soon as is feasibly possible in order to identify the correct diagnosis. If HRCT is not diagnostic then BAL and/or lung biopsy should be considered. BAL studies suggest that a lymphocytic BAL differential, particularly with an increased proportion of CD4+ cells, supports the diagnosis of MTX-P [44]. However, BAL, HRCT and lung biopsy data need further elaboration before the diagnosis of MTX-P can be made because the whole clinical picture can be blurred by the presence of CTD-associated ILD. Moreover, an important issue is that infection, as a reason for deterioration, needs to be excluded. MTX-P is not related to the cumulative or weekly dose of MTX and can even occur up to 4 months after discontinuation of the drug $[45,46]$. In patients with RA resistant to MTX therapy, tumour necrosis factor- $\alpha$ blocking agents can be used (i.e. etanercept, infliximab and adalimumab) [47-49]. Infliximab has been found to stabilise the progression of pulmonary fibrosis associated with RA [50]. These drugs can also be used in RA patients with early disease [51]. They are well tolerated and the side-effects include local reactions at the injection site, upper respiratory tract infections and an increased susceptibility to tuberculosis. A fatal exacerbation of RA-associated fibrosing alveolitis in patients treated with infliximab has also been described [52]. Cyclosporine has been used to treat both acute pneumonitis and progressive pulmonary fibrosis with success in individual patients [53-56]. RA-IP patients can attain some benefit with long-term oxygen therapy and respiratory rehabilitation $[1,3,6]$. Lung transplantation is the final modality in late-phase RA-IP without other organ involvement. 


\section{SYSTEMIC SCLEROSIS (SCLERODERMA)}

SSc is a collagen tissue disorder in which pulmonary involvement is very frequent and is associated with poor prognosis [5759]. The most common pulmonary complications are fibrosing alveolitis of systemic sclerosis (FASSc), and pulmonary vascular disease, which is the leading cause of death in SSc [60], surpassing renal involvement. In SSc, $25 \%$ of all patients will develop clinically significant ILD and severe restrictive lung disease has been reported in 13\% [57-59]. Therefore, the identification and staging of pulmonary involvement is very important for the management of the disease. For many years, IPF and FASSc were considered to be histologically similar conditions, despite the better prognosis in FASSc [61]. Recent studies in SSc demonstrated that NSIP is the most common histological pattern, followed by UIP in SSc [62-64].

\section{Clinical and laboratory features}

There are two forms of SSc. One is limited SSc (70\%), with subcutaneous calcinosis, Raynaud's phenomenon, esophageal dismobility, sclerodactily and telangiectasias. The presence of positive circulating anticentromere antibodies is $70 \%$. Pulmonary hypertension is common in limited SSc. The second is diffuse SSc, in which cutaneous involvement occurs simultaneously with the Raynaud's phenomenon, antitopoisomerase antibodies are present in $30 \%$ of the patients and anticentromere antibodies are usually absent (present in $3 \%$ of the patients). ILD occurs in limited or diffuse SSc and lung involvement rarely precedes scleroderma, although there is a syndrome called SSc sine scleroderma described in patients exposed to inhaled mineral particles [65]. In addition, it has been reported that at the presentation of an IIP, the presence of a nucleolar-staining antinuclear antibody, telangiectasia, Raynaud's phenomenon with abnormal capillaroscopy findings, gastro-oesophageal reflux or pericardial disease, suggests underlying SSc [66]. These findings should assist clinicians in the evaluation and treatment of patients with otherwise undefined ILD. Furthermore, coexistence of one or more autoimmune diseases and sarcoidosis has been described in the literature [67].

Respiratory symptoms include dry cough and dyspnoea, even if dyspnoea on exercise may be masked by general debility. As mentioned for RA, PFTs are very important for the evaluation of pulmonary involvement in SSc. DL,CO levels correlated better than other lung function indices with the total morphological extent of disease on HRCT [68]. In limited SSc, an isolated reduction of DL,CO can be associated with pulmonary vascular disease and can be a predictor for the development of pulmonary hypertension [69]. It is believed that a reduction of $D \mathrm{~L}, \mathrm{CO}$ level below $50 \%$ of the predicted value is an important indication for the initiation of therapeutic intervention. Cardiopulmonary exercise testing and 6-min walk distance are also important for the evaluation of the functional status of SSc patients [24], they can identify factors limiting exercise [70,71], evaluate the effect of pharmacological or nonpharmacological interventions [72] and predict survival [73]. However, they do not lack cardinal limitations.

\section{Radiological features}

In CVD-IP, chest radiography has a limited value. In contrast, HRCT has a greater sensitivity and improves the diagnosis. Although the imaging features of SSc-associated ILD have been extensively studied [74], more recent work with HRCT, together with the reclassification of the IPs, has led to a greater understanding of the condition. Currently, the consensus is that NSIP is the most common subtype, knowledge in part based on information obtained from HRCT studies, given that lung biopsies are performed only in a minority of cases. In a study of 225 patients, DESAI et al. [75] showed that the HRCT findings in SSc most closely resembled those of NSIP, typified by a predominant pattern of ground glass opacification and fine reticular opacities. HRCT has also been used to study longitudinally the lung disease in scleroderma. In a recent study, LAUNAY et al. [76] followed patients with predominantly ILD over a 5-yr period. They reported that approximately half of patients with ground glass abnormalities at initial computed tomography (CT) progressed to coarser fibrosis and honeycombing, whereas only $15 \%$ of subjects with a normal initial CT showed evidence of progression at 5 yrs.

\section{Bronchoalveolar lavage}

BAL is a valuable diagnostic tool for ruling out infection or confirming the presence of alveolitis. Alveolitis can be operationally defined as an increase in neutrophils $>3 \%$ or eosinophils $>2 \%$ of total cells on the BAL cell differential count. The prognostic value of BAL neutrophilia is questionable. On one hand, there are studies that have observed that BAL neutrophilia is associated with more progressive disease, especially in untreated patients, and therapy with oral cyclophosphamide has found to be associated with a better outcome [77-79]. Based on these data, BAL should be performed routinely in FASSc and have an important role on therapeutic decisions [80]. In addition, previous studies have shown that BAL neutrophilia is generally associated with extensive fibrotic disease, whereas a BAL eosinophilia is often seen in less advanced disease, particularly when CT appearances suggest lung inflammation [81, 82].

However, in a very recent study by $\mathrm{GoH}$ et al. [83], in which BAL cellular profiles have been studied in patients with SSc-IP, it has been shown that BAL findings do not have a prognostic value in disease progression, once disease severity is quantified by PFTs and HRCT. Early mortality (occurring within 2 yrs of presentation) is associated with BAL neutrophilia independent of disease severity, whereas late mortality (occurring 2-10 yrs after presentation) is not associated with BAL neutrophilia. As far as the other constituents of BAL are concerned, both BAL eosinophilia and lymphocytosis are not associated with mortality, rapidity of functional deterioration, or progression-free survival. These findings are unaltered when treatment status is taken into account [83]. In order to evaluate whether lavage cellularity identifies distinct subsets of disease and/or predicts cyclophosphamide responsiveness, lavage was performed in 201 patients as part of a randomised placebo-controlled trial of cyclophosphamide versus placebo (Scleroderma Lung Study) [84]. Abnormal cellularity was present in 101 of these cases and defined a population with a higher percentage of males, more severe lung function, more extensive ground glass opacity and more extensive fibrosis in the right middle lobe. Despite the aforementioned relationships, the presence or absence of an abnormal cell differential was not found as an independent predictor of disease progression or response to cyclophosphamide at 1 yr [85]. 
The conclusion that BAL has little to offer in routine prognostic evaluation in SSc-ILD is based upon the similarity of findings in these separate cohorts, with varying methodologies and analytic strategies, complementary strengths and differing limitations. Nevertheless, because of variability in reporting of cell counts and difficulties in interpretation, treatment decisions should not be based on BAL findings alone. A limited role for BAL cannot be wholly discounted if there is uncertainty regarding treatment decisions following routine staging, but this applies to highly selected patient subgroups and has not been captured in recent analyses.

\section{Lung biopsy}

The study by Bouros et al. [62] has shown that in 80 patients with lung biopsy-proven SSc-ILD, 5-yr survival differs little between UIP/end-stage lung disease (82\%) and NSIP (91\%), or between the subtypes of NSIP (cellular and fibrotic). Survival was linked to the level of lung function impairment, BAL eosinophil levels, and changes in DL,CO (but not FVC) during the first 3 yrs of follow-up. In a smaller series (19 patients), KIM et al. [64] have observed that the prognosis of NSIP is better than the prognosis of UIP. In conclusion, lung biopsy is less warranted as far as prognostic evaluation of SSc is concerned, except in cases with unusual HRCT appearances.

\section{Serum biomarkers}

The most promising markers implicated in the diagnosis, prognosis, choice and response to treatment in SSc are serum surfactant proteins (SPs) A and D, and mucine-like high molecular weight glycoprotein Krebs KL-6, which are produced by alveolar type-II epithelial cells. In one study, it has been observed that the concentration of SP-A and SP-D were significantly higher in patients with SSc-IP than in SSc patients without IP [86]. KL-6 has been also found to be higher in patients with SSc-IP than in patients without IP and healthy controls. Serum levels of these biomarkers have shown to inversely correlate with VC and DL,CO levels [87]. However, its sensitivity and specificity regarding disease activity is unclear, as increased serum and BAL levels of KL-6 are found in a variety of ILDs.

Autoantibodies such as anticentromerase and antitopoisomerase-I are thought to be more useful in predicting the development of IP than the nature of the skin disease [88, 89]. In fact, in patients with limited SSc and anticentromere antibody positivity, severe pulmonary fibrosis is rare, whereas patients with diffuse SSc and antitopoisomerase positivity need to be strictly monitored in order to initiate an early treatment.

\section{Treatment}

Until recently no proven effective therapy to prevent disease progression or reverse fibrosis existed. Corticosteroids represent one of the first-line drugs used in the therapy of SSc-IP, despite the fact that evidence of their efficacy is lacking. These drugs are also associated with scleroderma renal crisis (SRC), which was first shown in the study by STEEN and MEDSGER [90]. A dose of $15 \mathrm{mg} \cdot$ day $^{-1}$ of prednisone over a period of 6 months was associated with SRC. In the study by DEMARCO et al. [91] it has been observed that prednisone was associated with SRC only when high skin scores and large joint contractures were present, but surprisingly the mean dose was only $7.4 \mathrm{mg} \cdot$ day $^{-1}$. The efficacy of oral cyclophosphamide has been studied by WHITE et al. [79] who observed that oral administration of the drug in patients with BAL neutrophilia was associated with stabilisation or improvement in FVC and DL,CO and a better survival than in untreated patients, whereas in treated patients the outcome was similar to that in untreated patients without BAL neutrophilia.

Two prospective placebo-controlled multicentre clinical trials have been recently completed in SSc patients with alveolitis. The North American Scleroderma Lung study evaluated the efficacy of 12 month's oral cyclophosphamide $2 \mathrm{mg} \cdot \mathrm{kg}^{-1}$ versus placebo in 162 patients [84]. The main outcome measure was change in FVC \% pred. Secondary outcome measures included changes in TLC and DL,CO \% pred, and several measures of dyspnoea, quality of life and functional indices. It was found, at 12 months, that patients treated with cyclophosphamide had significantly less change in FVC compared with placebotreated patients. Oral cyclophosphamide also had a beneficial effect by improving dyspnoea, functional ability, health-related quality of life and skin thickness [84]. The group of oral cyclophosphamide had more adverse effects due to the drug such as leukopenia and neutropenia than the placebo group but the risk/benefit ratio seems to be favourable [84]. A second year of follow-up was performed in order to determine if these effects persisted after stopping treatment [92]. Using a longitudinal joint model, the authors analysed FVC, TLC, transitional dyspnoea index, Rodnan skin scores and the Health Assessment Questionnaire Disability Index during the second year after adjusting for baseline values, baseline fibrosis score and nonignorable missing data. It was found that, except for a sustained impact on dyspnoea, all other effects waned and were no longer apparent at 24 months.

Intravenous administration of cyclophosphamide is preferred to oral administration because of the lower risk of toxicity and, particularly, of bladder cancer. Intravenous administration of cyclophosphamide seems to have less adverse effects [93]. There are three studies in which efficacy of i.v. cyclophosphamide administered for 6 months (once monthly), in combination with corticosteroids in patients with SSc-IP has been studied [94-96]. The Fibrosing Alveolitis in Scleroderma Trial, conducted in the UK, investigated the effects of prednisone (20 mg q.o.d.) with six infusions (monthly) of i.v. cyclophosphamide $600 \mathrm{mg} \cdot \mathrm{m}^{-2}$ followed by oral azathioprine, versus matched placebo [97]. At 12 months there was a statistically significant difference in active treatment versus placebo in FVC. This treatment difference was $4.76 \%$ favouring cyclophosphamide compared with placebo $(\mathrm{p}=0.04)$ [97].

Most importantly, outcomes in both studies [84, 97] clearly show that in SSc-ILD, the treatment effect largely represents the prevention of progression of fibrotic disease.

Endothelin is overexpressed in two forms of ILD: IPF and pulmonary fibrosis due to scleroderma. Endothelin blockade with bosentan may provide a new treatment opportunity. Trials with bosentan in IPF (the BUILD (Bosentan Use in Interstitial Lung Disease)-1 trial) and pulmonary fibrosis secondary to scleroderma (BUILD-2) were initiated in 2003. In November 2005, the results of the studies showed that 
bosentan had no effect on the primary end-point of exercise improvement as measured by the 6-min walk test. The fact that in BUILD-2 no effect on either primary or secondary outcomes was shown could be related to the slow progression of the disease (pulmonary fibrosis related to SSc) observed in the study population, which was in contrast to the more severe and more rapidly progressive disease observed in BUILD-1. In conclusion, bosentan should not be used in SSc-ILD.

\section{SJÖGREN'S SYNDROME}

SS is an inflammatory CTD that is characterised by lymphocytic infiltration of the exocrine glands resulting in the sicca syndrome [98]. SS can occur alone as primary SS (pSS) or in association with other CVDs, such as RA, SLE and progressive SSc, known as secondary SS [99]. pSS may also have extraglandular manifestations affecting pulmonary, renal and small vasculature [100]. The frequency of pulmonary involvement varies from $9 \%$ to $75 \%$ depending on the detection method employed, and consists of various forms of small airway disease and ILDs [101-104]. Various histological patterns of ILDs have been associated with pSS, such as NSIP, UIP, OP, LIP, primary pulmonary lymphoma and diffuse interstitial amyloidosis. In earlier studies, it has been observed that LIP and primary pulmonary lymphoma were the dominant patterns in patients with pSS-IP [101-104]. Pulmonary lymphomas, which may present as solitary or multiple opacities, nodules or masses, and diffuse interstitial lesions with cysts in some cases may be indistinguishable from other benign lesions, such as LIP [105]. In recent studies it has been observed that NSIP is the most frequent pattern [106, 107]. This difference may be explained by the recent revision that took place in the recent classification criteria for IIPs [1] and, because of this, some cases previously classified as LIP may be now classified as NSIP.

\section{Clinical and laboratory features}

According to American-European classification criteria, the diagnosis of pSS is based on the following items: ocular symptoms of inadequate tear production, ocular signs of corneal damage due to inadequate tearing, oral symptoms of decreased saliva production, salivary gland histopathology demonstrating foci of lymphocytes, test results indicating impaired salivary gland function, and the presence of autoantibodies (anti-SS-A/Ro or anti-SS-B/La, or both). Definite diagnosis requires the presence of four of the six items with histopathological findings or autoantibodies being one of the four items [108]. Pulmonary manifestation most commonly includes exertional dyspnoea and dry cough with inspiratory crackles being the most frequent finding on physical examination. PFTs usually indicate a restrictive pattern with a decrease of DL,CO, TLC [109] and VC [104].

\section{Radiological features}

Data regarding the extent and incidence of respiratory involvement in SS vary widely depending on the methodologies used to investigate the disease. In patients with pSS, it has been found that bilateral lung infiltrates is the most common pattern seen on chest radiography [109]. It also has been found that in patients with both pSS and secondary SS, $22 \%$ had chest radiography abnormalities, with linear and reticular opacities being the most frequent finding [110].
HRCT findings in SS include both interstitial and airway abnormalities. The most commonly observed signs are ground glass opacities, nodules and thin-walled cysts [74]. This combination of signs is in accordance with LIP. In the study by MATSUYAMA et al. [110] in patients with both pSS and secondary SS, it has been observed that centrilobular abnormalities and lymphoproliferative disorders pattern were characteristic in patients with pSS.

Honeycombing and pulmonary fibrosis are reported to be relatively uncommon features of SS [75]. In the study by PARAMBIL et al. [109], in a retrospective analysis of 18 patients with pSS, HRCT features appeared to correlate relatively well with the underlying histopathological pattern of ILD. PARAMBIL et al. [109] also found that NSIP and OP were the most common pathologies, with UIP and LIP being less frequent. This would be consistent with the HRCT observation (in other nonbiopsy studies) in which ground glass opacities and consolidation were the predominant patterns [74]. In addition, HRCTpathological correlation resulted in a $94 \%$ positive predictive value of CT-NSIP pattern for pathological diagnosis of NSIP, and the 5-yr survival rate was found to be $83 \%$ in patients with NSIP [105]. In contrast, the diagnostic value of HRCT was low (15\%) with a HRCT pattern other than NSIP, data that may influence the decision to perform a biopsy [105].

\section{Bronchoalveolar lavage}

BAL has demonstrated the high prevalence of subclinical lymphocytic and neutrophilic alveolitis, affecting 50\% of patients with SS [111]. Alveolitis is more frequent in patients with extrapulmonary involvement. Neutrophilic alveolitis and an increase of CD8+ T-lymphocytes are associated with alteration of lung function [112, 113].

\section{Lung biopsy}

As previously mentioned, lung biopsy no longer has a place as a diagnostic procedure for CVD-IPs and adds little to the prognosis of the disease. In patients with SS-IP, lung biopsy is rarely required, with the exception of cases with HRCT patterns other than NSIP, because the diagnostic value of HRCT is low in these cases. So, these patients may have to undergo lung biopsy in order to diagnose or exclude malignant lymphoma [104].

\section{Serum biomarkers}

The presence of autoantibodies, and particularly anti-SS-A/Ro and anti-SS-B/La, is crucial for the diagnosis of SS. Other useful laboratory markers include polyclonal hypergammaglobulinaemia, elevated erythrocyte sedimentation rate, elevated titre of rheumatoid factor and the presence of antinuclear antibodies.

\section{Treatment}

Currently there is no consensus for the treatment of SS. Corticosteroids are commonly used as first-line therapy. Pulmonary symptoms seem to improve within several weeks but improvement in PFTs and radiological findings occur over a course of few to several months [109]. Among the histopathological patters of SS, OP seems to respond better to corticosteroid therapy. Immunosuppressive agents such as azathioprine and cyclophosphamide can also be used but their role in the therapy of SS-IP is not yet clear. 


\section{POLYMYOSITIS/DERMATOMYOSITIS}

$\mathrm{PM}$ and DM are systemic inflammatory diseases affecting skeletal muscles and other organs, especially the lungs. Pulmonary involvement in PM/DM may precede muscle and skin manifestations and includes respiratory muscle weakness, aspiration pneumonia, ILD, ventilatory insufficiency, infections and drug-induced pneumonia [114-117]. ILD, which develops in $23.1-65.0 \%$ of PM/DM patients [116, 118-120], is a major cause of death in this disease [116, 119, 121-123]. ILD leads to life-threatening complications, such as ventilatory failure, secondary pulmonary arterial hypertension and cor pulmonale [116, 117, 121, 122, 124-127], so the early detection of ILD is a high priority in PM/DM patients. However, in PM/DM patients a careful search for underlying malignancies is strongly advocated. Poor prognostic factors of ILD in PM/DM have been reported to include a HammanRich-like pattern, low creatine kinase levels, low DL,CO, neutrophilic BAL and lung histology of DAD or UIP [119, $123,128,129]$. The 3-yr mortality rate of the chronic-type patients $(21.2 \%)$ was not found to be significantly different from that of the patients without ILD (10.2\%) [130]. In addition, the acute, severe form of ILD is not infrequent with a high mortality rate and no response to steroid treatment [130].

\section{Clinical and laboratory features}

The diagnosis of PM/DM is based on the criteria described by BoHAN and Peter [131, 132]: 1) systemic muscle weakness; 2) increased serum muscle enzymes; 3) myopathic changes on electromyopathy; 4) typical histological findings on muscle biopsy; and 5) characteristic dermatological manifestations (heliotrope rash, periungual erythema, Gotton's papules and poikiloderma). Pulmonary involvement may precede by many years or occur simultaneously, or follow the muscular manifestations [133].

Four main types of clinical presentations of ILD associated with PM/DM have been reported: 1) acute presentation ( $<2$ weeks) with fever, dyspnoea and lung infiltrates; 2) insidious onset of dyspnoea, cough and lung infiltrates; 3) asymptomatic pulmonary infiltrates without respiratory symptoms; and 4) abnormal PFTs and HRCT with normal chest film [134]. No correlation has been found between the extent and severity of the muscle or skin disease and the development of ILD [135]. Arthritis is more common in PM/DM with ILD [118, 119].

\section{Radiological features}

The CT patterns of lung involvement associated with HRCT in PM/DM vary widely among patients [136]. There are many types of radiographic abnormalities on HRCT, including parenchymal micronodules and nodules, linear opacities, irregularity of the interfaces between peripheral pleura and aerated lung parenchyma, ground glass opacities, honeycombing and traction bronchiectases or bronchiolectases [124, 126, $127,137]$. These findings were localised predominantly in the pulmonary lower zones. Studies have shown that NSIP is the most common form of ILD [3, 106, 124]. In one of the aforementioned studies, DougLAs et al. [124] scrutinised HRCT findings in 30 patients with $\mathrm{PM} / \mathrm{DM}$, of whom 22 underwent a surgical lung biopsy. They observed the following: consolidation in $53 \%$, irregular linear opacities in $43 \%$, ground glass opacities in $43 \%$, pleural effusions in $20 \%$, and no honeycombing in any patients. The above features were seen in 18 cases of NSIP, two cases of DAD, and one case each of UIP and OP [124]. ARAKAWA et al. [137] reported similar results in 14 cases of PM/DM with histologically proven NSIP. Consolidation is also a regular finding in other studies [138, 139]. Although there was no histological confirmation, it was suggested that these findings correlated with an OP. Often patients with PM/DM have both NSIP and OP. Rarely, LIP and UIP are found in PM/DM [3]. One more manifestation of PM/DM is a sudden respiratory decompensation, as seen in AIP. The radiological features of this, which correspond to the histological findings of DAD, are extensive ground glass opacities and consolidation, with no subpleural predominance [138].

\section{Bronchoalveolar lavage}

There are few reports that have included data about the BAL cell profiles in PM/DM patients with ILD. However, BAL cell differential may be a helpful prognostic indicator in PM/DM patients with ILD. Patients with ILD had poor outcome when the initial BAL showed neutrophilic alveolitis [119].

\section{Lung biopsy}

Lung biopsy has no diagnostic value for PM/DM, but the histological appearance was useful for determining the prognosis under treatment [129]. In PM/DM, NSIP is much more frequent than a UIP, OP or LIP pattern [124]. Patients with $\mathrm{OP}$ have a more favourable prognosis than those with UIP, and patients with DAD have a uniformly poor prognosis [119, 129, 140-143].

\section{Serum biomarkers}

Antisynthetase antibodies are detected in $40-80 \%$ of patients with PM and ILD (anti-Jo1 being the most frequent) [119, 124, $144,145]$. Anti-Jo1 is present in $23 \%$ of all patients with PM. SP-D serum levels have been found to be higher in patients with PM/DM and ILD compared with patients without lung involvement and healthy controls [146]. Similarly, serum levels of KL-6, a glycoprotein expressed on type-II alveolar pneumocytes and bronchial epithelial cells, have been found to be increased in PM/DM patients with interstitial lung involvement when compared with patients without parenchymal disease and healthy controls [147]. Finally, SP-D is suggested to be a useful marker in patients with PM/DM [146].

\section{Treatment}

Corticosteroids, either oral or i.v., are used as initial treatment (prednisone $40-60 \mathrm{mg} \cdot \mathrm{day}^{-1}$ ) [148]. Patients failing to respond to corticosteroids should be treated with cytotoxic agents [144]. Although data are limited to small series and case reports, responses have been noted with cyclophosphamide, azathioprine, MTX, cyclosporine A and racrolimus, even in patients failing to respond to corticosteroids [148]. Although useful in refractory PM, i.v. immunoglobulins have not been evaluated for their effect on lung involvement [149].

\section{SYSTEMIC LUPUS ERYTHEMATOSOUS}

SLE is as autoimmune disease characterised by disturbances in innate and adaptive immune mechanisms. SLE primarily affects females. Multiple systems and organs may be involved. Tissue damage and dysfunction are mediated by autoantibodies and immune complex formation. The respiratory system is frequently 
involved by the disease and respiratory involvement is more common in males than in females. Pulmonary manifestations usually occur in patients with multisystem disease and include pleural involvement, parenchymal disease, atelectasis, pulmonary vascular disease, diaphragmatic dysfunction and upper airway dysfunction [150]. The pulmonary manifestations may range from subclinical abnormalities to life-threatening disorders. Many of these manifestations are seen in the antiphospholipid syndrome (APS) as well as in both the primary and secondary syndrome. The catastrophic APS may affect the lung in up to $66 \%$ of cases and may present with acute respiratory distress syndrome, pulmonary embolism, pulmonary artery thrombosis, in situ microthrombi, or even with alveolar haemorrhage [151]. Moreover, cases in which APS presentation was associated with fibrosis and/or alveolitis have been reported. However, the prevalence and severity of ILD in SLE is considerably lower than that in other CVDs.

\section{Clinical features}

The diagnosis of SLE is based on the criteria of the American College of Rheumatology, which were updated in 1997 [152]. Although lung involvement is not a criterion for SLE diagnosis, lung involvement has been associated with increased mortality $[153,154]$

Acute lupus pneumonitis is an uncommon manifestation of SLE affecting $1.4-4 \%$ of patients. The typical manifestations include dyspnoea, cough fever, pleuritic pain and possible haemoptysis. Pulmonary haemorrhage is a rare but lifethreatening manifestation occurring in $<2 \%$ of SLE patients. It carries a poor prognosis with mortality rates of $70-90 \%$.

Diffuse ILD is relatively uncommon in SLE, although it may dominate the clinical picture in some patients. This involvement of the lung affects $3-8 \%$ of SLE patients. The onset may be insidious, with a chronic nonproductive cough, dyspnoea on exertion and recurrent pleuritic pain.

\section{Radiological features}

Initial studies suggested a very low incidence based on chest radiography [74]. However, two HRCT series have demonstrated a higher rate of ILD features. FENLON et al. [155] have found evidence of ILD in one third of patients with SLE, although the majority of them were classified as mild involvement. Only two of the 34 patients included in the study had honeycombing [155]. Moreover, BANKIER et al. [156] also found pulmonary fibrosis in one third of 45 asymptomatic SLE patients, confirming the ability of HRCT to demonstrate subclinical disease. Importantly, in both reports, interlobular septal thickening was the most frequent interstitial abnormality. Moreover, no correlation has been found between HRCT appearances and symptoms, disease duration, doublestranded DNA titres, smoking history or nonpulmonary involvement in a prospective study of 29 SLE patients [157]. However, the authors observed unusually prevalent HRCT appearances suggestive of ILD in patients with SLE, suggesting that subclinical lung disease is common [157].

Although acute lupus pneumonitis and pulmonary alveolar haemorrhage are histopathologically distinct, the imaging features are similar and distinguishing between them can be difficult. Bilateral airspace opacification (consolidation and ground glass opacities) are found in both conditions [74]. Rapid resolution of radiological changes may favour pulmonary haemorrhage, whereas acute lupus pneumonitis may be accompanied by pleural effusions [74]. The chest radiography and CT scans of acute lupus pneumonitis show uni- or bilateral alveolar infiltrates which usually predominate in the lower lobes. LIP has been described in a few patients with SLE [74]. In these cases, the development of lung cysts should suggest the diagnosis of LIP [158-160]. Finally, the clinicoradiological syndrome of OP characterised by patchy alveolar infiltrates has been described in patients with SLE [161-163].

\section{Bronchoalveolar lavage}

In patients with both SLE and APS a lower than normal CD4+/ CD8+ ratio in BAL was seen, suggesting subclinical ILD in patients who were asymptomatic regarding respiratory symptoms [164].

\section{Lung biopsy}

Acute lupus pneumonitis is characterised by DAD microscopically, whereas in pulmonary alveolar haemorrhage a neutrophilic capillaritis is the pathological hallmark [165]. In chronic interstitial pulmonary disease of SLE, histological reports describe nonspecific abnormalities with interstitial lymphocytic infiltrates, interstitial fibrosis and honeycomb changes [166, 167]. The incidence of NSIP in SLE is not well defined [106]. Nevertheless, available evidence indicates that the pulmonary fibrosis shown by HRCT in SLE is most in keeping with NSIP pattern [74]. It seems likely that a proportion of these patients may have developed fibrosis following an initial lupus pneumonitis.

\section{Serum biomarkers}

Lung involvement does not correlate with any biological marker, although in one study an association between antiSS-A antibodies and chronic IP has been observed [168]. However, this observation was not confirmed in later studies, which described only an association between low DL,CO and anti-U1 ribonucleoprotein (RNP) antibodies [169].

\section{Treatment}

Acute lupus pneumonitis, which is often accompanied by capillaritis with diffuse alveolar haemorrhage, is often a lethal pulmonary complication of SLE with a mortality rate $>50 \%$ [170]. It is crucial to start treatment of life-theatening haemorrhage promptly. Although there is lack of controlled studies for the treatment of acute lupus pneumonitis and diffuse alveolar haemorrhage, the current recommendations are based on case reports and clinical experience. Preferred treatment is pulse methylprednisolone $\left(1,000 \mathrm{mg} \cdot\right.$ day $^{-1}$ for three consecutive days) alone or in combination with pulse or oral cyclophosphamide [171]. Corticosteroids and immunosuppressive drugs are routinely used to treat UIP, NSIP, OP and LIP in patients with SLE, although the effectiveness of these therapies has not been verified by controlled trials.

\section{MIXED CONNECTIVE TISSUE DISEASE}

MCTD was first described in 1972 as a distinct overlap characterised by features of systemic SSc, SLE and PM/DM, with respiratory involvement occurring in $80 \%$ of patients [172] 
A prerequisite for the diagnosis of MCTD is the presence of high titres of antibodies against uridine-rich RNA-small nuclear RNP (anti-RNP) [173].

Clinical features include a high frequency of Raynaud's syndrome, swollen hands, sclerodactyly, arthritis, PM and ILD [174]. The major respiratory manifestations include ILD and pulmonary fibrosis (20-65\%), pleural effusion (50\%) and pulmonary hypertension (10-45\%). Other pulmonary disorders are pulmonary vasculitis, pulmonary thromboembolism, pulmonary infections (secondary to aspiration pneumonia due to oesophageal motility alterations and immunosuppression), alveolar haemorrhage, pulmonary nodules, pulmonary cysts, mediastinal lymphadenopathy and respiratory muscle dysfunction.

Given that the clinical features of the condition include aspects of all the above disorders, a spectrum of radiological features might be expected. However, the HRCT features of MCTD are not extensively studied. In one study of 41 patients, abnormalities were common with ground glass attenuation found in all patients, while nodules and reticular opacities were also frequently seen, predominantly in the peripheral lower zones [175]. Honeycombing was less common. Overall, the authors commented that the appearances were similar to that of NSIP and UIP. It is interesting to note that no cases of mosaic attenuation were found, and other signs of airways disease were less frequently observed than in, for example, RA. As with SSc, proximal pulmonary artery enlargement due to pulmonary hypertension, as well as oesophageal abnormalities, are found in MCTD [176]. Pleural effusions and pleural thickening are also seen, which resembles SLE [154].

The most frequent causes of death in patients with MCTD are pulmonary hypertension $(26.1 \%)$, respiratory insufficiency $(23.2 \%)$ and heart failure $(15.9 \%)$ [177]. Thus, the cause of death in MCTD patients is quiet different from those of SLE and SSc patients [178, 179]. Pulmonary hypertension has not been demonstrated to be the primary cause of death in either SLE or SSc patients. The prevalence of pulmonary hypertension in MCTD patients has been reported as $4 \%$ [180, 181].

As in other CTD, there are no controlled data on which to base the therapy for interstitial lung involvement in MCTD. In general, most disorders are treated with corticosteroids and/or immunosuppressive agents, which are directed against the autoimmune-driven mononuclear cell infiltration in the lung parenchyma. Interstitial fibrosis is irreversible but treatment may be warranted, primarily in the hope of preventing or slowing down its progression. Regimens used for IP in SSc appear appropriate and usually consist of low-dose corticosteroids in combination with cyclophosphamide or azathioprine $[182,183]$.

\section{CONCLUSIONS}

Interstitial lung involvement is common and potentially lifethreatening in CVDs. Every patient with CTD deserves a thorough work-up, in order to be investigated whether lung involvement is present, and if so, to what degree. Routine checking includes clinical evaluation, lung function and clinical exercise tests, imaging modalities, BAL, lung biopsy, and use of some serum biomarkers, like KL-6 and SP-D. Early detection of pulmonary involvement is very important for the initiation of a targeted therapy, because the damage to the lung parenchyma may be already irreversible at the time of the onset of respiratory symptoms.

HRCT is less useful in the key distinction between subclinical and clinically significant disease. No cut-off for disease extent exists at which it can be concluded that the illness has become clinically important. Informal evaluation of the extent of disease on HRCT is a useful exercise because abnormalities are clearly limited or clearly extensive in the majority of cases. However, in the remaining cases, it is necessary to base judgements of disease severity on pulmonary function evaluation (especially $\mathrm{DL}, \mathrm{CO}$ ). The introduction of treatment for ILD in CTD requires the clinician to discriminate between "reversible" disease, in which a response is expected and highdose therapy is often warranted, and fibrotic disease, in which long-term treatment is used to slow or prevent progression of disease. HRCT is prognostically useful in CTD, usually for the identification of a minority of cases in which appearances are likely to be reversible. Although the radiation dose associated with CT is low with interspaced HRCT protocols, patients with CTD are, on average, younger than those with IIPs, and clinicians should properly perform CT as frequently as it is necessary. Moreover, pulmonary function trends are helpful in many cases, whether disclosing stability or disease progression, and the additional information known by serial HRCT is unlikely to refine management. BAL is advocated for its role in excluding other causes of parenchymal involvement in CTD, e.g. infections, drug reactions and capillaritis with diffuse alveolar haemorrhage. Therefore, the decision of whether to treat is a challenging one, and should be based on evaluation of disease severity (on the basis of CT extent and lung function) and longitudinal disease behaviour. Recent advances in scleroderma lung clearly showed that treatment effect amounts largely to the prevention of progression of fibrotic disease. However, because of the significant toxicity of cyclophosphamide, the assessment of alternative, less toxic, immunosuppressive agents for the long-term management of $\mathrm{SSC}_{\mathrm{C}}$ associated ILD is needed.

The final conclusion is that every patient with collagen vascular disease should be thoroughly evaluated for lung involvement and, vice versa, in every diffuse interstitial lung disease pattern a connective tissue disorder should be investigated.

\section{REFERENCES}

1 Crestani B. The respiratory system in connective tissue disorders. Allergy 2005; 60: 715-734.

2 American Thoracic Society/European Respiratory Society. International Multidisciplinary Consensus Classification of the Idiopathic Interstitial Pneumonias. Am J Respir Crit Care Med 2002; 165: 277-304.

3 Kim DS. Interstitial lung disease in rheumatoid arthritis: recent advances. Curr Opin Pulm Med 2006; 12: 346-353.

4 Kinder BW, Collard HR, Koth L, et al. Idiopathic nonspecific interstitial pneumonia: lung manifestation of undifferentiated connective tissue disease? Am J Respir Crit Care Med 2007; 176: 691-697.

5 Horton MR. Rheumatoid arthritis associated interstitial lung disease. Crit Rev Comput Tomogr 2004; 45: 429-440. 
6 Maradit-Kremers H, Nicola PJ, Crowson CS, Ballman KV, Gabriel SE. Cardiovascular death in rheumatoid arthritis: a population-based study. Arthritis Rheum 2005; 52: 722-732.

7 Lee HK, Kim DS, Yoo B, et al. Histopathologic pattern and clinical features of rheumatoid arthritis-associated interstitial lung disease. Chest 2005; 127: 2019-2027.

8 Yoshinouchi T, Ohtsuki Y, Fujita J, et al. Nonspecific interstitial pneumonia pattern as pulmonary involvement of rheumatoid arthritis. Rheumatol Int 2005; 26: 121-125.

9 Saag KG, Kolluri S, Koehnke RK, et al. Rheumatoid arthritis lung disease. Determinants of radiographic and physiologic abnormalities. Arthritis Rheum 1996; 39: 1711-1719.

10 Tanaka N, Kim JS, Newell JD, et al. Rheumatoid arthritisrelated lung diseases: CT findings. Radiology 2004; 232: 81-91.

11 Lamblin C, Bergoin C, Saelens T, Wallaert B. Interstitial lung diseases in collagen vascular diseases. Eur Respir J 2001; 32: Suppl. 45, 69s-80s.

12 Nicholson AG, Colby TV, Wells AU. Histopathological approach to patterns of interstitial pneumonia in patient with connective tissue disorders. Sarcoidosis Vasc Diffuse Lung Dis 2002; 19: 10-17.

13 Brown KK. Rheumatoid Lung Disease. Proc Am Thorac Soc 2007; 4: 443-448.

14 Akira M, Sakatani M, Hara H. Thin-section CT findings in rheumatoid arthritis associated lung disease: CT patterns and their courses. J Comput Assist Tomogr 1999; 23: 941-948.

15 Park JH, Kim DS, Park IN, et al. Prognosis of fibrotic interstitial pneumonia: idiopathic versus collagen vascular disease-related subtypes. Am J Respir Crit Care Med 2007; 175: 705-711.

16 Fujita J, Ohtsuki Y, Yoshinouchi T, et al. Idiopathic nonspecific interstitial pneumonia: as an "autoimmune interstitial pneumonia". Respir Med 2005; 99: 234-240.

17 Sato T, Fujita J, Yamadori I, et al. Nonspecific interstitial pneumonia; as the first clinical presentation of various collagen vascular disorders. Rheumatol Int 2006; 26: 551-555.

18 Rajasekaran BA, Shovlin D, Lord P, Kelly CA. Interstitial lung disease in patients with rheumatoid arthritis: a comparison with cryptogenic fibrosing alveolitis. Rheumatology (Oxford) 2001; 40: 1022-1025.

19 Dawson JK, Fewins HE, Desmond J, Lynch MP, Graham DR. Fibrosing alveolitis in patients with rheumatoid arthritis as assessed by high resolution computed tomography, chest radiography, and pulmonary function tests. Thorax 2001; 56: 622-627.

20 Banks J, Banks C, Cheong B, et al. An epidemiological and clinical investigation of pulmonary function and respiratory symptoms in patients with rheumatoid arthritis. Q J Med 1992; 85: 795-806.

21 Dawson JK, Fewins HE, Desmond J, Lynch MP, Graham DR. Predictors of progression of HRCT diagnosed fibrosing alveolitis in patients with rheumatoid arthritis. Ann Rheum Dis 2002; 61: 517-521.

22 Risk C, Epler GR, Gaensler EA. Exercise alveolar-arterial oxygen pressure difference in interstitial lung disease. Chest 1984; 85: 69-74.
23 Orens JB, Kazerooni EA, Martinez FJ, et al. The sensitivity of high-resolution $\mathrm{CT}$ in detecting idiopathic pulmonary fibrosis proved by open lung biopsy. A prospective study. Chest 1995; 108: 109-115.

24 Chetta A, Aiello M, Foresi A, et al. Relationship between outcome measures of six-minute walk test and baseline lung function in patients with interstitial lung disease. Sarcoidosis Vasc Diffuse Lung Dis 2001; 18: 170-175.

25 Lama VN, Flaherty KR, Toews GB, et al. Prognostic value of desaturation during a 6-minute walk test in idiopathic interstitial pneumonia. Am J Respir Crit Care Med 2003, 168: 1084-1090

26 McDonagh J, Greaves M, Wright AR, Heycock C, Owen JP, Kelly C. High resolution computed tomography of the lungs in patients with rheumatoid arthritis and interstitial lung disease. Br J Rheumatol 1994; 33: 118-122.

27 Cortet B, Flipo RM, Rémy-Jardin M, et al. Use of high resolution computed tomography of the lungs in patients with rheumatoid arthritis. Ann Rheum Dis 1995; 54: 815-819.

28 Provenzano G. Asymptomatic pulmonary involvement in RA. Thorax 2002; 57: 187-188.

29 Ayhan-Ardic FF, Oken O, Yorgancioglu ZR, Ustun N, Gokharman FD. Pulmonary involvement in lifelong nonsmoking patients with rheumatoid arthritis and ankylosing spondylitis without respiratory symptoms. Clin Rheumatol 2006; 25: 213-218.

30 Bilgici A, Ulusoy H, Kuru O, Celenk C, Unsal M, Danaci M. Pulmonary involvement in rheumatoid arthritis. Rheumatol Int 2005; 25: 429-435.

31 Biederer J, Schnabel A, Muhle C, Gross WL, Heller M, Reuter M. Correlation between HRCT findings, pulmonary function tests and bronchoalveolar lavage cytology in interstitial lung disease associated with rheumatoid arthritis. Eur Radiol 2004; 14: 272-280.

32 Zrour SH, Touzi M, Bejia I, et al. Correlations between high-resolution computed tomography of the chest and clinical function in patients with rheumatoid arthritis: prospective study in 75 patients. Joint Bone Spine 2005; 72 41-47.

33 Dawson JK, Graham DR, Desmond J, Fewins HE, Lynch MP. Investigation of the chronic pulmonary effects of low-dose oral methotrexate in patients with rheumatoid arthritis: a prospective study incorporating HRCT scanning and pulmonary function tests. Rheumatology (Oxford) 2002; 41: 262-267.

34 Garcia JG, Parhami N, Killam D, Garcia PL, Keogh BA. Bronchoalveolar lavage fluid evaluation in rheumatoid arthritis. Am Rev Respir Dis 1986; 133: 450-454.

35 Gilligan DM, O'Connor CM, Ward K, Moloney D, Bresnihan B, FitzGerald MX. Bronchoalveolar lavage in patients with mild and severe rheumatoid lung disease. Thorax 1990; 45: 591-596.

36 Gauhar UA, Gaffo AL, Alarcón GS. Pulmonary manifestations of rheumatoid arthritis. Semin Respir Crit Care Med 2007; 28: 430-440.

37 Tanoue LT. Pulmonary manifestations of rheumatoid arthritis. Clin Chest Med 1998; 19: 667-685.

38 Zisman DA, McCune WJ, Tino G, Lynch JP III. Druginduced pneumonitis: the role of methotrexate. Sarcoidosis Vasc Diffuse Lung Dis 2001; 18: 243-252. 
39 Carson CW, Cannon GW, Egger MJ, Ward JR, Clegg DO. Pulmonary disease during the treatment of rheumatoid arthritis with low dose pulse methotrexate. Semin Arthritis Rheum 1987; 16: 186-195.

40 Searles G, McKendry RJ. Methotrexate pneumonitis in rheumatoid arthritis: potential risk factors. Four case reports and a review of the literature. J Rheumatol 1987; 14: 1164-1171.

41 Kremer JM, Alarcón GS, Weinblatt ME, et al. Clinical, laboratory, radiographic, and histopathologic features of methotrexate-associated lung injury in patients with rheumatoid arthritis: a multicenter study with literature review. Arthritis Rheum 1997; 40: 1829-1837.

42 Padley SP, Adler B, Hansell DM, Muller NL. Highresolution computed tomography of drug induced lung disease. Clin Radiol 1992; 46: 232-236.

43 Hacking JC, Flower CD. Causes and investigation of increasing dyspnoea in rheumatoid arthritis. Ann Rheum Dis 1995; 54: 17-19.

44 Fuhrman C, Parrot A, Wislez M, et al. Spectrum of CD4 to CD8 T-cell ratios in lymphocytic alveolitis associated with methotrexate-induced pneumonitis. Am J Respir Crit Care Med 2001; 164: 1186-1191.

45 Barrera P, Laan RF, van Riel PL, Dekhuijzen PN, Boerbooms AM, van de Putte LB. Methotrexate-related pulmonary complications in rheumatoid arthritis. Ann Rheum Dis 1994; 53: 434-439.

46 Elsasser S, Dalquen P, Soler M, Perruchoud AP. Methotrexate-induced pneumonitis: appearance four weeks after discontinuation of treatment. Am Rev Respir Dis 1989; 140: 1089-1092.

47 Elliott MJ, Maini RN, Feldmann M, et al. Randomised double-blind comparison of chimeric monoclonal antibody to tumour necrosis factor alpha (cA2) versus placebo in rheumatoid arthritis. Lancet 1994; 344: 1105-1110.

48 Moreland LW, Baumgartner SW, Schiff MH, et al. High resolution computed tomography in fibrosing alveolitis associated with systemic sclerosis. J Rheumatol 2006; 33: 1789-1801.

49 van de Putte LB, Atkins C, Malaise M, et al. Efficacy and safety of adalimumab as monotherapy in patients with rheumatoid arthritis for whom previous disease modifying antirheumatic drug treatment has failed. Ann Rheum Dis 2004; 63: 508-516.

50 Antoniou KM, Mamoulaki M, Malagari K, et al. Infliximab therapy in pulmonary fibrosis associated with collagen vascular disease. Clin Exp Rheumatol 2007; 25: 23-28.

51 Bathon JM, Martin RW, Fleischmann RM, et al. A comparison of etanercept and methotrexate in patients with early rheumatoid arthritis. N Engl J Med 2000; 343: 1586-1593.

52 Ostor AJ, Crisp AJ, Somerville MF, Scott DG. Fatal exacerbation of rheumatoid arthritis associated fibrosing alveolitis in patients given infliximab. BMJ 2004; 329: 1266.

53 Turesson C, Matteson EL. Management of extra-articular disease manifestations in rheumatoid arthritis. Curr Opin Rheumatol 2004; 16: 206-211.

54 Chang HK, Park W, Ryu DS. Successful treatment of progressive rheumatoid interstitial lung disease with cyclosporine: a case report. J Korean Med Sci 2002; 17: 270-273.

55 Puttick MP, Klinkhoff AV, Chalmers A, Ostrow DN. Treatment of progressive rheumatoid interstitial lung disease with cyclosporine. J Rheumatol 1995; 22: 2163-2165.

56 Ogawa D, Hashimoto H, Wada J, et al. Successful use of cyclosporin A for the treatment of acute interstitial pneumonitis associated with rheumatoid arthritis. Rheumatology (Oxford) 2000; 39: 1422-1424.

57 Ferri G, Valentini G, Cozzi F, et al. Systemic sclerosis: demographic, clinical and serological features and survival in 1,012 Italian patients. Medicine (Baltimore) 2002; 81: 139-153.

58 Scussel-Lonzetti L, Joyal F, Raynauld J-P, et al. Predicting mortality in systemic sclerosis: analysis of a cohort of 309 French Canadian patients with emphasis on features at diagnosis and survival. Medicine (Baltimore) 2002; 81: 154-167.

59 Simeón CP, Armadans L, Fonollosa V, et al. Mortality and prognostic factors in Spanish patients with systemic sclerosis. Rheumatology 2003; 42: 71-75.

60 Altman RD, Medsger TA Jr, Bloch DA, Michel BA. Predictors of survival in systemic sclerosis (scleroderma). Arthritis Rheum 1991; 34: 403-413.

61 Wells AU, Cullinan P, Hansell DM, et al. Fibrosing alveolitis associated with systemic sclerosis has a better prognosis than lone cryptogenic fibrosing alveolitis. Am J Respir Crit Care Med 1994; 149: 1583-1590.

62 Bouros D, Wells AU, Nicholson AG, et al. Histopathologic subsets of fibrosing alveolitis in patients with systemic sclerosis and their relationship to outcome. Am J Respir Crit Care Med 2002; 165: 1581-1586.

63 Fujita J, Yoshinouchi T, Ohtsuki Y, et al. Non-specific interstitial pneumonia as pulmonary involvement of systemic sclerosis. Ann Rheum Dis 2001; 60: 281-283.

64 Kim DS, Yoo B, Lee JS, et al. The major histopathologic pattern of pulmonary fibrosis in scleroderma is nonspecific interstitial pneumonia. Sarcoidosis Vasc Diffuse Lung Dis 2002; 19: 121-127.

65 Lomeo RM, Cornella RJ, Schabel SI, Silver RM. Progressive systemic sclerosis sine scleroderma presenting as pulmonary interstitial fibrosis. Am J Med 1989; 87: 525-527.

66 Fischer A, Meehan RT, Feghali-Bostwick CA, West SG, Brown KK. Unique characteristics of systemic sclerosis sine scleroderma-associated interstitial lung disease. Chest 2006; 130: 976-981.

67 Hosoya N, Mimura T, Enokawa Y, et al. A rare case of cardiac sarcoidosis in a patient with progressive systemic sclerosis, Sjögren's syndrome, and polymyositis. Intern Med 1995; 34: 1164-1167.

68 Wells AU, Hansell DM, Rubens MB, et al. Fibrosing alveolitis in systemic sclerosis: indices of lung function in relation to extent of disease on computed tomography. Arthritis Rheum 1997; 40: 1229-1236.

69 Steen V, Medsger TA Jr. Predictors of isolated pulmonary hypertension in patients with systemic sclerosis and limited cutaneous involvement. Arthritis Rheum 2003; 48: 516-522.

70 Medinger AE, Khouri S, Rohatgi PK. Sarcoidosis: the value of exercise testing. Chest 2001; 120: 93-101. 
71 Spruit MA, Thomeer MJ, Gosselink R, et al. Skeletal muscle weakness in patients with sarcoidosis and its relationship with exercise intolerance and reduced health status. Thorax 2005; 60: 32-38.

72 Azuma A, Nukiwa T, Tsuboi E, et al. Double-blind, placebo-controlled trial of pirfenidone in patients with idiopathic pulmonary fibrosis. Am J Respir Crit Care Med 2005; 171: 1040-1047.

73 Kawut SM, O'Shea MK, Bartels MN, Wilt JS, Sonett JR, Arcasoy SM. Exercise testing determines survival in patients with diffuse parenchymal lung disease evaluated for lung transplantation. Respir Med 2005; 99: 1431-1439.

74 Devaraj A, Wells AU, Hansell DM. Computed tomographic imaging in connective tissue diseases. Semin Respir Crit Care Med 2007; 28: 389-397.

75 Desai SR, Veeraraghavan S, Hansell DM, et al. CT features of lung disease in patients with systemic sclerosis: comparison with idiopathic pulmonary fibrosis and nonspecific interstitial pneumonia. Radiology 2004; 232: 560-567.

76 Launay D, Remy-Jardin M, Michon-Pasturel U, et al. High resolution computed tomography in fibrosing alveolitis associated with systemic sclerosis. J Rheumatol 2006; 33: 1789-1801.

77 Silver RM, Miller KS, Kinsella MB, Smith EA, Schabel SI. Evaluation and management of scleroderma lung disease using bronchoalveolar lavage. Am J Med 1990; 88: 470-476.

78 Behr J, Vogelmeier C, Beinert T, et al. Bronchoalveolar lavage for evaluation and management of scleroderma disease of the lung. Am J Respir Crit Care Med 1996; 154: 400-406.

79 White B, Moore WC, Wigley FM, Xiao HQ, Wise RA Cyclophosphamide is associated with pulmonary function, survival benefit in patients with scleroderma and alveolitis, Arch Intern Med 2000; 132: 947-954.

80 White B. Evaluation and management of pulmonary fibrosis in scleroderma. Curr Rheumatol Rep 2002; 4: 108-112.

81 Wells AU, Hansell DM, Rubens MB, et al. Fibrosing alveolitis in systemic sclerosis: bronchoalveolar lavage findings in relation to computed tomographic appearances. Am J Respir Crit Care Med 1994; 150: 462-468.

82 Wells AU, Hansell DM, Haslam PL, et al. Bronchoalveolar lavage cellularity: lone cryptogenic fibrosing alveolitis compared with the fibrosing alveolitis of systemic sclerosis. Am J Respir Crit Care Med 1998; 157: 1474-1482.

83 Goh NS, Veeraraghavan S, Desai SR, et al. Bronchoalveolar lavage cellular profiles in patients with systemic sclerosis-associated interstitial lung disease are not predictive of disease progression. Arthritis Rheum 2007; 56: 2005-2012.

84 Tashkin DP, Elashoff R, Clements PJ, et al. Cyclophosphamide versus placebo in scleroderma lung disease. N Engl J Med 2006; 354: 2655-2666.

85 Strange C, Bolster MB, Roth MD, et al. Bronchoalveolar lavage and response to cyclophosphamide in scleroderma interstitial lung disease. Am J Respir Crit Care Med 2008; 177: 91-98.

86 Takahashi H, Kuroki Y, Tanaka H, et al. Serum levels of surfactant proteins $\mathrm{A}$ and $\mathrm{D}$ are useful biomarkers for interstitial lung disease inpatients with progressive systemic sclerosis. Am J Respir Crit Care Med 2000; 162: 258-263.

87 Yanaba K, Hasegawa M, Takehara K, Sato S. Comparative study of serum surfactant protein-D and KL-6 concentrations in patients with systemic sclerosis as markers for monitoring the activity of pulmonary fibrosis. J Rheumatol 2004; 31: 1112-1120.

88 Steen V. Predictors of end stage lung disease in systemic sclerosis. Ann Rheum Dis 2003; 62: 97-99.

89 Tashkin DP, Clements PJ, Wright RS, et al. Interrelationships between pulmonary and extrapulmonary involvement in systemic sclerosis: a longitudinal analysis. Chest 1994; 105: 489-495.

90 Steen VD, Medsger TA Jr. Case-control study of corticosteroids and other drugs that could precipitate or protect from the development of scleroderma renal crisis. Arthritis Rheum 1998; 41: 1613-1619.

91 DeMarco PJ, Weisman MH, Seibold JR, et al. Predictors and outcomes of scleroderma renal crisis: the high-dose versus low-dose D-penicillamine in early diffuse systemic sclerosis trial. Arthritis Rheum 2002; 46: 2983-2989.

92 Tashkin DP, Elashoff R, Clements PJ, et al. Effects of 1year treatment with cyclophosphamide on outcomes at 2 years in scleroderma lung disease. Am J Respir Crit Care Med 2007; 176: 1026-1034.

93 Petri M. Cyclophosphamide: new approaches for systemic lupus erythematous. Lupus 2004; 13: 366-371.

94 Pakas I, Ioannidis JP, Malagari K, Skopouli FN, Moutsopoulos HM, Vlachoyiannopoulos PG. Cyclophosphamide with low or high dose prednisolone for systemic sclerosis lung disease. J Rheumatol 2002; 29: 298-304

95 Giacomelli R, Valentini G, Salsano F, et al. Cyclophosphamide pulse regimen in the treatment of alveolitis in systemic sclerosis. J Rheumatol 2002; 29: 731-736.

96 Griffiths B, Miles S, Moss H, Robertson R, Veale D, Emery P. Systemic sclerosis and interstitial lung disease: a pilot study using pulse intravenous methylprednisolone and cyclophosphamide to assess the effect on high resolution computed tomography scan and lung function. J Rheumatol 2002; 29: 2371-2378.

97 Hoyles RK, Ellis RW, Wellsbury J, et al. A multicenter, prospective, randomized, double-blind, placebo-controlled trial of corticosteroids and intravenous cyclophosphamide followed by oral azathioprine for the treatment of pulmonary fibrosis in scleroderma. Arthritis Rheum 2006; 54: 3962-3970.

98 Bloch KJ, Buchanan WW, Wohl MJ, Bunim JJ. Sjögren's syndrome: a clinical, pathological, and serological study of sixty-two cases. Medicine 1965; 44: 187-231.

99 Moutsopoulos HM, Chused TM, Mann DL, et al. Sjögren's syndrome (Sicca syndrome): current issues. Ann Intern Med 1980; 92: 212-226.

100 Manthorpe R, Asmussen K, Oxholm PJ. Primary Sjögren's syndrome: diagnostic criteria, clinical features, and disease activity. Rheumatology 1997; 24: 8-11.

101 Deheinzelin D, Capelozzi VL, Kairalla RA, Barbas Filho JV, Saldiva PH, de Carvalho CR. Interstitial lung 
disease in primary Sjögren's syndrome: clinical-pathological evaluation and response to treatment. Am J Respir Crit Care Med 1996; 154: 794-799.

102 Cain HC, Noble PW, Matthay RA. Pulmonary manifestations of Sjögren's syndrome. Clin Chest Med 1998; 19: 687-699.

103 Davidson BKS, Kelly CA, Griffiths ID. Ten-year follow up of pulmonary function in patients with primary Sjögren's syndrome. Thorax 2000; 59: 709-712.

104 Ito I, Nagai S, Kitaichi M, et al. Pulmonary manifestations of primary Sjögren's syndrome: a clinical, radiologic, and pathologic study. Am J Respir Crit Care Med 2005; 171: 632-638.

105 Honda O, Johkoh T, Ichikado K, et al. Differential diagnosis of lymphocytic interstitial pneumonia and malignant lymphoma on high-resolution CT. AJR Am J Roentgenol. 1999; 173: 71-74.

106 Tansey D, Wells AU, Colby TV, et al. Variations in histological patterns of interstitial pneumonia between connective tissue disorders and their relationship to prognosis. Histopathology 2004; 44: 585-596.

107 Yamadori I, Fujita J, Bandoh S, et al. Nonspecific interstitial pneumonia as pulmonary involvement of primary Sjögren's syndrome. Rheumatol Int 2002; 22: 89-92.

108 Vitali C, Bombardieri S, Jonsson R, et al. Classification criteria for Sjögren's syndrome: a revised version of the European criteria proposed by the American-European Consensus Group. Ann Rheum Dis 2002; 61: 554-558.

109 Parambil JG, Myers JL, Lindell RM, Matteson EL, Ryu JH. Interstitial lung disease in primary Sjögren syndrome. Chest 2006; 130: 1489-1495.

110 Matsuyama N, Ashizawa K, Okimoto T, Kadota J, Amano H, Hayashi K. Pulmonary lesions associated with Sjögren's syndrome: radiographic and CT findings. Br J Radiol 2003; 76: 880-884.

111 Hatron PY, Wallaert B, Gosset D, et al. Subclinical lung inflammation in primary Sjögren's syndrome. Relationship between bronchoalveolar lavage cellular analysis findings and characteristics of the disease. Arthritis Rheum 1987; 30: 1226-1231.

112 Wallaert B, Prin L, Hatron PY, Ramon P, Tonnel AB, Voisin C. Lymphocyte subpopulations in bronchoalveolar lavage in Sjögren's syndrome. Evidence for an expansion of cytotoxic/suppressor subset in patients with alveolar neutrophilia. Chest 1987; 92: 1025-1031.

113 Wallaert B, Hatron PY, Grosbois JM, Tonnel AB, Devulder B, Voisin C. Subclinical pulmonary involvement in collagen-vascular diseases assessed by bronchoalveolar lavage. Am Rev Respir Dis 1986; 133: 574-580.

114 Callen JP. Dermatomyositis. Lancet 2000; 355: 53-57.

115 Marie I, Hachulla E, Hatron PY, et al. Polymyositis and dermatomyositis: short term and long term outcome, and predictive factors of prognosis. J Rheumatol 2001; 28: 2230-2237.

116 Marie I, Hatron PY, Hachulla E, Wallaert B, MichonPasturel U, Devulder B. Pulmonary involvement in polymyositis and in dermatomyositis. J Rheumatol 1998; 25: 1336-1343.

117 Marie I, Hatron PY, Levesque H, et al. Influence of age on characteristics of polymyositis and dermatomyositis in adults. Medicine 1999; 78: 139-147.
118 Fathi M, Dastmalchi M, Rasmussen E, Lundberg IE, Tornling G. Interstitial lung disease, a common manifestation of newly diagnosed polymyositis and dermatomyositis. Ann Rheum Dis 2004; 63: 297-301.

119 Marie I, Hachulla E, Chérin $\mathrm{P}$, et al. Interstitial lung disease in polymyositis and dermatomyositis. Arthritis Rheum 2002; 47: 614-622.

120 Hirakata M, Nakamura K, Kaburaki J, et al. : Interstitial lung disease in patients with connective tissue diseases.: Nihon Kyobu Shikkan Gakkai Zasshi 1995;33: Suppl., 268-276..

121 Lakhanpal S, Lie JT, Conn DL, Martin WJ 2nd, Pulmonary disease in polymyositis/dermatomyositis: a clinicopathological analysis of 65 autopsy cases. Ann Rheum Dis 1987; 46: 23-29.

122 Arsura EL, Greenberg AS. Adverse impact of interstitial pulmonary fibrosis on prognosis in polymyositis and dermatomyositis. Semin Arthritis Rheum 1988; 18: 29-37.

123 Takizawa H, Shiga J, Moroi Y, Miyachi S, Nishiwaki M, Miyamoto T. Interstitial lung disease in dermatomyositis: clinicopathological study. J Rheumatol 1987; 14: 102-107.

124 Douglas WW, Tazelaar HD, Hartman TE, et al. Polymyositis-dermatomyositis-associated interstitial lung disease. Am J Respir Crit Care Med 2001; 16: 1182-1185.

125 Grau JM, Miró O, Pedrol E, et al. Interstitial lung disease related to dermatomyositis. Comparative study with patients without lung involvement. J Rheumatol 1996; 23: 1921-1926.

126 Hirakata M, Nagai S. Interstitial lung disease in polymyositis and dermatomyositis. Curr Opin Rheumatol 2000; 12: 501-508.

127 Marie I, Dominique S, Rémy-Jardin M, Hatron PY, Hachulla E. Interstitial lung diseases in polymyositis and dermatomyositis. Rev Med Interne 2001; 22: 1083-1096.

128 Schnabel A, Reuter M, Biederer J, Richter C, Gross WL. Interstitial lung disease in polymyositis and dermatomyositis: clinical course and response to treatment. Semin Arthritis Rheum 2003; 32: 273-284.

129 Tazelaar HD, Viggiano RW, Pickersgill J, Colby TV. Interstitial lung disease in polymyositis and dermatomyositis. Clinical features and prognosis as correlated with histologic findings. Am Rev Respir Dis 1990; 141: 727-733.

130 Won Huh J, Soon Kim D, Keun Lee C, et al. Two distinct clinical types of interstitial lung disease associated with polymyositis-dermatomyositis. Respir Med 2007; 101: 1761-1769.

131 Bohan A, Peter JB. Polymyositis and dermatomyositis (first of two parts). N Engl J Med 1975; 292: 344-347.

132 Bohan A, Peter JB. Polymyositis and dermatomyositis (second of two parts). N Engl J Med 1975; 292: 403-407.

133 Yang Y, Fujita J, Tokuda M, Bandoh S, Ishida T. Chronological evaluation of the onset of histologically confirmed interstitial pneumonia associated with polymyositis/dermatomyositis. Intern Med 2002; 41: 1135-1141.

134 Frazer RS, Muller NL, Colman N, et al. International pneumonitis in association with polymyositis and dermatomyositis. In: Fraser R, Muller N, Colman N, Pare P, eds. 
Diagnosis Of Diseases Of The Chest. London, Saunders, 1999; pp. 1462-1465.

135 Marvin I, Schwarz MD. Pulmonary and cardiac manifestations of polymyositis-dermatomyosytis. J Thor Imaging 1992; 7: 46-54.

136 Bonnefoy O, Ferretti G, Calaque O, et al. Serial chest CT findings in interstitial lung disease associated with polymyositis-dermatomyositis. Eur J Radiol 2004; 49: 235-244.

137 Arakawa H, Yamada H, Kurihara Y, et al. Nonspecific interstitial pneumonia associated with polymyositis and dermatomyositis: serial high-resolution CT findings and functional correlation. Chest 2003; 123: 1096-1103.

138 Akira M, Hara H, Sakatani M. Interstitial lung disease in association with polymyositis-dermatomyositis: longterm follow-up CT evaluation in seven patients. Radiology 1999; 210: 333-338.

139 Mino M, Noma S, Taguchi Y, Tomii K, Wu CL, Chen PJ. Pulmonary involvement in polymyositis and dermatomyositis: sequential evaluation with CT. AJR Am J Roentgenol 1997; 169: 83-87.

140 Ito M, Kaise S, Suzuki S, et al. Interstitial lung disease in amyopathic dermatomyositis, dermatomyositis and polymyositis. Eur Respir J 2003; 22: 245-250.

141 Lee CS, Chen TL, Tzen CY, et al. Idiopathic inflammatory myopathy with diffuse alveolar damage. Clin Rheumatol 2002; 21: 391-396.

142 Kazenstein AA, Fiorelli RF. Non specific interstitial pneumonia/fibrosis: Histologic features and clinical significance. Am J Surg Pathol 1994; 18: 136-147.

143 Kang EH, Lee EB, Shin KC, et al. Interstitial lung disease in patients with polymyositis, dermatomyositis and amyopathic dermatomyositis. Rheumatology (Oxford) 2005; 44: 1282-1286.

144 Cottin V, Thivolet-Béjui F, Reynaud-Gaubert M, Cadranel J. Interstitial lung disease in amyopathic dermatomyositis, dermatomyositis and polymyositis. Eur Respir J 2003; 22: 245-250.

145 Evans J. Antinuclear antibody testing in systemic autoimmune disease. Clin Chest Med 1998; 19: 613-625.

146 Ihn H, Asano Y, Kubo M, et al. Clinical significance of serum surfactant protein D (SP-D) in patients with polymyositis/dermatomyositis: correlation with interstitial lung disease. Rheumatology 2002; 41: 1268-1272.

147 Bandoh S, Fujita J, Ohtsuki Y, et al. Sequential changes of KL-6 in sera of patients with interstitial pneumonia associated with polymyositis/dermatomyositis. Ann Rheum Dis 2000; 59: 257-262.

148 Deng J, Keane MP, Lynch III JP. Pulmonary complications of polymyositis and dermatomyositis. In: Wells AU, Denton $\mathrm{CP}$, eds. Pulmonary Involvement in Systemic Autoimmune Diseases. London, Elsevier, 2004; pp. 209-226.

149 Cherin P, Pelletier S, Teixeira A, et al. Results and longterm follow up of intravenous immunoglobulin infusions in chronic, refractory polymyositis: an open study with thirty-five adult patients. Arthritis Rheum 2002; 46: 467-474.

150 King TE Jr, Cherniack RM, Schwarz MI. The lungs and connective tissue diseases. In: Murray JF, Nadel JA, eds. Textbook Of Respiratory Medicine. Philadelphia: WB Saunders, 1994; pp. 1850-1872.
151 Asherson RA, Cervera R, Piette JC, et al. Catastrophic antiphospholipid syndrome. Clinical and laboratory features of 50 patients. Medicine (Baltimore) 1998; 77: 195-207.

152 Hochberg MC. Updating American College of Rheumatology revised criteria for the classification of systemic lupus erythematosous. Arhritis Rheum 1997; 40: 1725.

153 Cervera R, Khamashta MA, Font J, et al. Morbidity and mortality in systemic lupus erythematosus during a 5year period. A multicenter prospective study of 1,000 patients. European Working Party on Systemic Lupus Erythematosus. Medicine (Baltimore) 1999; 78: 167-175.

154 Murin S, Wiedemann HP, Matthay RA. Pulmonary manifestations of systemic lupus erythematosus. Clin Chest Med 1998; 19: 641-665.

155 Fenlon HM, Doran M, Sant SM, Breatnach E. High resolution CT in systemic lupus erythematosus. AJR Am J Roentgenol 1996; 166: 301-307.

156 Bankier AA, Kiener HP, Wiesmayr MN, et al. Discrete lung involvement in systemic lupus erythematosus: CT assessment. Radiology 1995; 196: 835-840.

157 Sant SM, Doran M, Fenelon HM, Breatnach ES. Pleuropulmonary abnormalities in patients with systemic lupus erythematosus: assessment with high resolution computed tomography, chest radiography and pulmonary function tests. Clin Exp Rheumatol 1997; 15: 507-513.

158 Filipek MS, Thompson ME, Wang PL, Gosselin MV, L Primack S. Lymphocytic interstitial pneumonitis in a patient with systemic lupus erythematosus: radiographic and high-resolution CT findings. J Thorac Imaging 2004; 19: 200-203.

159 Yood RA, Steigman DM, Gill LR. Lymphocytic interstitial pneumonitis in a patient with systemic lupus erythematosus. Lupus 1995; 4: 161-163.

160 Yum HK, Kim ES, Ok KS, Lee HK, Choi SJ. Lymphocytic interstitial pneumonitis associated with Epstein-Barr virus in systemic lupus erythematosus and Sjögren's Syndrome. Complete remission with corticosteriod and cyclophosphamide. Korean J Intern Med 2002; 17: 198-203.

161 Min JK, Hong YS, Park SH, et al. Bronchiolitis obliterans organizing pneumonia as an initial manifestation in patients with systemic lupus erythematosus. J Rheumatol 1997; 24: 2254-2257.

162 Otsuka F, Amano T, Hashimoto N, et al. Bronchiolitis obliterans organizing pneumonia associated with systemic lupus erythematosus with antiphospholipid antibody. Intern Med 1996; 35: 341-344.

163 Gammon RB, Bridges TA, al-Nezir H, Alexander CB, Kennedy JI Jr. Bronchiolitis obliterans organizing pneumonia associated with systemic lupus erythematosus. Chest 1992; 102: 1171-1174.

164 Paran D, Koifman B, Elkayam O, et al. Echocardiography, pulmonary function testing and induced sputum evaluation in systemic lupus erythematosous and the antiphospholipid syndrome. Lupus 2002; 11: 546.

165 Myers JL, Katzenstein AA. Microangiitis in lupusinduced pulmonary hemorrhage. Am J Clin Pathol 1986; 85: 552-556.

166 Eisenberg $H$, Dubois EL, Sherwin RP, Balchum OJ. Diffuse interstitial lung disease in systemic lupus erythematosus. Ann Intern Med 1973; 79: 37-45. 
167 Weinrib L, Sharma OP, Quismorio FP Jr. A long-term study of interstitial lung disease in systemic lupus erythematosus. Semin Arthritis Rheum 1990; 20: 48-56.

168 Boulware DW, Hedgpeth MT. Lupus pneumonitis and anti-SSA(Ro) antibodies. J Rheumatol 1989; 16: 479-481.

169 Groen H, ter Borg EJ, Postma DS, Wouda AA, van der Mark TW, Kallenberg CG. Pulmonary function in systemic lupus erythematosus is related to distinct clinical, serologic, and nailfold capillary patterns. Am J Med 1992; 93: 619-627.

170 Leatherman JW, Davies SF, Hoidal JR. Alveolar hemorrhage syndromes: diffuse microvascular lung hemorrhage in immune and idiopathic disorders. Medicine (Baltimore) 1984; 63: 343-361.

171 Schwab EP, Schumacher HR Jr, Freundlich B, Callegari PE. Pulmonary alveolar hemorrhage in systemic lupus erythematosus. Semin Arthritis Rheum 1993; 23: 8-15.

172 Sharp GC, Irvin WS, Tan EM, Gould RG, Holman HR. Mixed connective tissue disease-an apparently distinct rheumatic disease syndrome associated with a specific antibody to an extractable nuclear antigen (ENA). Am J Med 1972; 52: 148-159.

173 Kasukawa R, Sharp GC. Mixed Connective Tissue Diseases and Antinuclear Antibodies. Amsterdam, Elsevier, 1987.

174 Venables PJ. Mixed connective tissue disease. Lupus 2006; 15: 132-137.

175 Prakash UB. Respiratory complications in mixed connective tissue disease. Clin Chest Med 1998; 19: 733-746.

176 Kozuka T, Johkoh T, Honda O, et al. Pulmonary involvement in mixed connective tissue disease: high-resolution CT findings in 41 patients. J Thorac Imaging 2001; 16: 94-98.

177 Tojo T, Ogasawara T, Aotsuka S, Yokohari R. Major Causes of Death and Five Year Survival Rates in Mixed
Connective Tissue Disease. 1990 Annual Report of the Research Committee of Japanese Ministry of Health and Welfare for Mixed Connective Tissue Disease. Japanese Ministry of Health and Welfare, 1991; pp. 10-13.

178 Ichikawa Y, Tsunematsu T, Yokohari R, et al. Multicenter study of causes of death in systemic lupus erythematosous - a report from Subcommittee for Development of Therapy, the Research Committee for Autoimmune Diseases Supported by Ministry of Health and Welfare. Ryumachi 1985; 25: 258-264.

179 Kaburaki J, Lee CC, Ogasawara T, Okano H, Tojo T. Clinical study of progressive systemic sclerosis (PSS) patients with poor prognosis. Annual Report of the Ministry of Health and Welfare Scleroderma Research Committee 1998. Japanese Ministry of Health and Welfare, 1998; pp. 314-318.

180 Esther JH, Sharp GH, Agia G, Hurst DJ, Maricq HR. Pulmonary hypertension in a patient with connective tissue disease and antibody to nuclear ribonucleoprotein. Arthritis Rheum 1981; 24: 2105.

181 Miyawaki S, Onodera H, Kasukawa R, Nishimaki T. Multicenter study on therapy and prognosis of mixed connective tissue disease. In: Kasukawa $\mathrm{R}$, ed. Proceedings of the Symposium on Therapy, Disease Type and Pulmonary Hypertension of Mixed Connective Tissue Disease. Research Committee of the Japanese Ministry of Health and Welfare for Mixed Connective Tissue Disease, 1991; pp. 26-35.

182 Latsi PI, Wells AU. Evaluation and management of alveolitis and interstitial lung disease in scleroderma. Curr Opin Rheumatol 2003; 15: 748-755.

183 Antoniou KM, Wells AU. Scerloderma lung disease: evolving understanding in light of newer studies. Curr Opin Rheumatol 2008; 20: 686-691. 